\title{
Anatomia foliar comparativa de nove espécies do gênero Piper (Piperaceae)
}

\author{
Comparative leaf anatomy of nine species of the genus Piper (Piperaceae)
}

\author{
Alessandra Mara Gogosz ${ }^{1,3}$, Maria Regina Torres Boeger ${ }^{1}$, Raquel Rejane Bonato Negrelle ${ }^{1}$ \& Celso Bergo ${ }^{2}$
}

\begin{abstract}
Resumo
As espécies de Piper são de grande interesse medicinal. Porém apresentam considerável desafio taxonômico, provavelmente pelo diminuto tamanho das partes florais. Por isso a morfologia externa da folha tem sido muito utilizada para taxonomia do grupo. Entretanto, há poucos trabalhos anatômicos para o gênero. Neste estudo, as folhas de nove espécies foram comparadas anatomicamente: Piper aduncum Vell.; P. cernuum Vell.; $P$. dilatatum Rich; P. gaudichaudianum Kunth; P. glabratum Kunth; P. hispidinervum C. DC.; P. lindbergii C. DC.; P. solmsianum C. DC. e P. umbellatum Jacq. O objetivo era avaliar o potencial dos caracteres anatômicos para separação de espécies. A maioria das espécies estudadas tem a epiderme do limbo constituída por células retangulares e arredondadas. Camadas subepidérmicas ocorrem em ambas às faces do limbo, exceto em $P$. aduncum, $P$. cernuum e P. hispidinervum. Todas as espécies são hipoestomáticas, exceto $P$. hispidinervum. O mesofilo é dorsiventral na maioria das espécies, enquanto em $P$. solmsianum e $P$. umbellatum o mesofilo é homogêneo. O número de camadas dos tecidos paliçádico e esponjoso é variável. Também ocorrem variações no número e no tamanho dos feixes vasculares. Em geral, ocorrem células secretoras, idioblastos, tricomas tectores e glandulares, lipídios, compostos fenólicos e amido. A análise de agrupamento identificou três grupos distintos entre as espécies, com base nas características anatômicas estudadas.
\end{abstract}

Palavras-chave: anatomia, folha, Piperaceae, Piper.

\begin{abstract}
The species of Piper are of great medical interest. They, however, represent considerable taxonomic challenge, probably due to the small size of floral parts. Therefore, the external morphology of the leaf has been used as diagnostic features in the taxonomy of the group. However, there are few anatomical studies on species of this genus. In this study, the leaves of nine species were compared anatomically: Piper aduncum Vell., P. cernuum Vell., P. dilatatum Rich, P. gaudichaudianum Kunth, P. glabratum Kunth, P. hispidinervum C. DC., P. lindbergii C. DC., P. solmsianum C. DC. and $P$. umbellatum Jacq. The objective was to evaluate the potential of anatomical characters for species separation. Most species studied have the epidermis of the lamina consists of rectangular and rounded cells. Subepidermal layers occur on both sides of the lamina, except in $P$. aduncum, $P$. cernuum and $P$. hispidinervum. All species are hypostomatic, except $P$. hispidinervum. The mesophyll is dorsiventral in most species, while in $P$. solmsianum and $P$. umbellatum, the mesophyll is homogeneous. The number of layers of palisade and spongy tissue is variable. Also there are variations in the number and size of vascular bundles. In general, secreting cells, idioblasts, and glandular trichomes, lipids, phenolic compounds and starch are present. Cluster analysis identified three distinct groups of species based on anatomical features studied.
\end{abstract} Key words: anatomy, leaves, Piperaceae, Piper.

\section{Introdução}

Piperaceae possui cerca de 2515 espécies, distribuídas em oito gêneros (Machado 2007). Compreende ervas, arbustos e arvoretas, frequentemente epífitas ou lianas. O caule é nodoso, as folhas são alternas, simples, com margem inteira, pecioladas, com ou sem estípulas (Guimarães \& Valente 2001; Souza \& Lorenzi

\footnotetext{
${ }^{1}$ Universidade Federal do Paraná, Depto. Botânica, Setor de Ciências Biológicas, Centro Politécnico, C.P. 19031, 81531-970 Curitiba, PR, Brasil.

${ }^{2}$ Universidade Federal do Paraná, Setor de Ciências Agrárias, Juvevê, R. dos Funcionários 1540, 80035-050 Curitiba, PR, Brasil.

${ }^{3}$ Autor para correspondência: alegogosz@gmail.com
} 
2005). Espécies dessa família encontram-se distribuídas por toda a América. No Brasil ocorrem cinco gêneros e cerca de 500 espécies, encontradas principalmente na Mata Atlântica (Souza \& Lorenzi 2005).

Diversas espécies do gênero Piper são usadas na medicina popular e muitas têm importância econômica, especialmente devido à presença de conteúdo oleífero em suas estruturas. Dentre as espécies com tal característica estão $P$. crassinervium H.B. \& K., conhecida como jaborandi, P. hispidinervum C.DC. (pimentalonga), $P$. aduncum L. (pimenta-de-macaco), $P$. nigrum (pimenta-do-reino), entre outras.

Segundo Metcalfe \& Chalk (1965), Piperaceae têm expressivo interesse anatômico devido à presença de sistema vascular com feixes dispersos, semelhante ao que ocorre nas monocotiledôneas. No entanto, Piperaceae difere das monocotiledôneas pelo fato de o crescimento em espessura ocorrer através da atividade cambial, como é típico em eucotiledôneas. Além disso, as folhas das espécies de Piperaceae mostram uma diversidade estrutural, especialmente entre os gêneros Peperomia, Piper e Ottonia (Souza et al. 2004).

Devido à presença dos óleos essenciais nas espécies de Piperaceae, vários estudos têm sido desenvolvidos a fim de identificar os componentes químicos presentes nas suas estruturas (Parmar et al. 1997; Martins et al. 1998; Silva \& Oliveira 2000; Mundina et al. 2001; Santos et al. 2001; Facundo et al. 2005; Morais et al. 2007; Sousa et al. 2008). No entanto, são poucas as informações disponíveis na literatura sobre a anatomia e morfologia das estruturas que contém esses componentes, nas espécies da família. Além disso, a maioria dos trabalhos de anatomia e morfologia de Piper caracterizam geralmente uma espécie, não havendo uma comparação interespecífica para tal gênero (Souza et al. 2004; Albiero et al. 2005a,b; Albiero et al. 2006; Sousa et al. 2008; Souza et al. 2009).

Segundo Machado (2007), o tamanho diminuto das partes florais e a uniformidade morfológica das partes vegetativas gera problemas taxonômicos em Piper. Neste contexto, o presente trabalho teve como objetivo o estudo anatômico das folhas de nove espécies do gênero Piper, visando avaliar o uso potencial dos caracteres anatômicos para separação interespecífica.

\section{Material e Métodos}

O material botânico foi coletado em junho de 2009, em uma área pertencente à empresa Solar

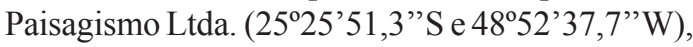
localizada no município de Morretes - PR, Brasil. A região é caracterizada por formação Floresta Ombrófila Densa, com clima subtropical, verões quentes, geadas pouco frequentes, sem estação seca definida. Segundo a Embrapa (1999), neste local encontram-se solo do tipo Cambissolos Flúvicos Tb Distróficos típicos.

Foram coletadas folhas adultas de três indivíduos de nove espécies de Piperaceae: Piper aduncum Vell.; P. cernuum Vell.; P. dilatatum Rich; P. gaudichaudianum Kunth; P. glabratum Kunth; P. hispidinervum C. DC.; P. lindbergii C. DC.; P. solmsianum C. DC. e P. umbellatum Jacq. localizadas entre o terceiro e sexto nó, no sentido ápice-base. As amostras coletadas foram fixadas em FAA 70, desidratadas em série alcoólica, emblocadas em resina de metacrilato e posteriormente, secionadas em micrótomo de rotação. Foram obtidas secções histológicas da região mediana da folha, sendo estas distendidas em lâminas, submetidas à coloração com azul de toluidina (O'Brien et al. 1964) e montadas em meio apropriado (Kraus \& Arduin 1997).

Para visualização dos tricomas e estômatos foi realizada diafanização das folhas. Posteriormente o material foi desidratado e montado em lâminas com água. As lâminas foram analisadas e os tecidos ilustrados com auxílio de câmara clara acoplada ao microscópio fotônico, no Laboratório de Botânica Estrutural da Universidade Federal do Paraná.

Foram também realizadas secções a mão livre, com navalha de aço descartável, de material fresco da região mediana da folha, para análises microquímicas com lugol (Berlyn \& Miksche 1976), para detectar amido; sudan III (Sass 1951), para detectar substâncias graxas e cloreto férrico 10\% (Johansen 1940), para detectar compostos fenólicos. As secções foram montadas em água. A análise do material e documentação fotográfica foi realizada com uma câmara digital acoplada ao microscópio fotônico Olympus CX40.

$\mathrm{Na}$ análise da epiderme em microscopia eletrônica de varredura (MEV) foram utilizadas amostras do terço médio das folhas, tanto da face adaxial como da abaxial. Estas foram fixadas em FAA 70 e desidratadas em série alcoólica. Em 
seguida, o material foi submetido ao método do ponto crítico no equipamento Balzers CPC 10. As amostras foram aderidas em suporte metálico com fita adesiva de carbono. Posteriormente, realizouse a metalização com ouro no equipamento Balzers Sputtering SCD 030. A análise e o registro eletromicrográfico do material foram efetuados no microscópio eletrônico (MEV) Jeol JSM-6360LV.

Para avaliar o grau de similaridade entre as espécies estudadas, foi realizada uma análise de agrupamento com base em ausência ( 0 ) ou presença (1) de caracteres, utilizando a distância Euclidiana e o método UPGMA. Foram consideradas significativas análises com índice cofenético superior a 0,7. A análise de agrupamento foi realizada com o auxílio do programa Statistica versao 7.0 (Statsoft Inc., USA).

\section{Resultados e Discussão}

A maioria das espécies estudadas tem a epiderme do limbo, nas faces adaxial e abaxial, constituída por células retangulares e circulares. As células da epiderme adaxial são maiores que as da face abaxial. Em algumas espécies percebe-se a forma convexa da parede periclinal externa (Fig. 1a-i).

Todas as espécies estudadas são hipoestomáticas, exceto $P$. hispidinervum que apresenta estômatos em ambas as faces do limbo. A distribuição anfiestomática contribui potencialmente para altas taxas de fotossíntese em folhas de sol (Smith et al. 1997). Foi constatado que o tipo de estômato mais frequente entre as espécies é o tetracítico, seguido de ciclocítico (Fig. 2a-i). Folhas hipoestomáticas são comuns entre as Piperaceae, assim como a presença de estômatos do tipo tetracíticos e ciclocíticos (Metcalfe \& Chalk 1965). Ainda neste contexto, Souza et al. (2004) sugere que o complexo estomático é uma característica pouco útil para a taxonomia de Piperaceae, considerando sua grande complexidade e variação morfológica. Além disso, foi possível observar que $P$. hispidinervum destaca-se das demais espécies pela grande quantidade de estômatos proeminentes, presentes principalmente, na face abaxial, característica também relatada por Santiago et al. (2001) para essa mesma espécie. Também se nota que, em $P$. gaudichaudianum e $P$. hispidinervum, os estômatos são bem elevados em relação às células epidérmicas comuns (Fig. 3a, b).
O mesofilo é caracterizado como dorsiventral na maioria das espécies (Fig. 1a-i). O número de camadas dos tecidos paliçádico e esponjoso é variável. $\mathrm{Na}$ maioria das espécies analisadas, o parênquima paliçádico é uniestratificado, exceto em $P$. aduncum, P. hispidinervum e P. lindbergii, que possuem duas camadas de células (Fig. 1a, $\mathrm{f}-\mathrm{g}$ ). Em geral, no parênquima esponjoso o número de camadas varia de duas a cinco (Fig. 1a-i). Tais resultados assemelham-se ao que ocorre em outras espécies de Piper já descritas, (Metcalfe \& Chalk 1965, 1979; Souza et al. 2004; Albiero et al. 2005a,b, 2006; Souza et al. 2009). A ocorrência de uma ou mais camadas de parênquima paliçádico nas folhas está potencialmente relacionada com a intensidade luminosa que atinge as folhas (Smith et al. 1997). O parênquima paliçádico apresenta células com formato colunar que possibilita a distribuição da luz mais eficientemente para o interior da folha. Em adição a isso, as células esféricas do parênquima esponjoso e os espaços de ar no interior da folha absorvem com mais eficiência a luz difusa, devido ao formato das suas células (Taiz \& Zeiger 2004). Embora tenham sido observadas diferenças entre as espécies quanto ao número das camadas dos parênquimas paliçádico e esponjoso, tais variações não representam um fator confiável para a distinção entre as espécies, por tratar-se de uma característica bastante influenciável pelas condições ambientais, especialmente a luz.

A região de transição entre o mesofilo e a nervura central é formada pela epiderme, pela epiderme múltipla e células de colênquima. Foi constatada a presença de epiderme múltipla em todas as espécies estudadas. No entanto, a maioria das espécies tem epiderme múltipla apenas na face adaxial (Fig. 1a-g), exceto P. solmsianum e $P$. umbellatum onde a epiderme múltipla ocorre em ambas às faces do limbo (Fig. 1h-i). Além disso, nota-se que o número das camadas da epiderme múltipla pode ser variável: $P$. aduncum, $P$. hispidinervum e $P$. lindbergii têm cerca de três camadas de células (Fig. 1a, f-g), enquanto que $P$. cernuum, $P$. dilatatum, $P$. gaudichaudianum, $P$. glabratum, $P$. solmsianum e $P$. umbellatum apresentam de uma a duas camadas de células (Fig. 1b-e, h-i). Metcalfe \& Chalk (1965, 1979) descrevem como hipoderme o tecido ocorrente abaixo da primeira camada de células (epiderme) nas espécies de Piperaceae, assim como Albiero et al. (2006) em P. hispidium. No entanto, Takemori et al. (2003) concluíram que 

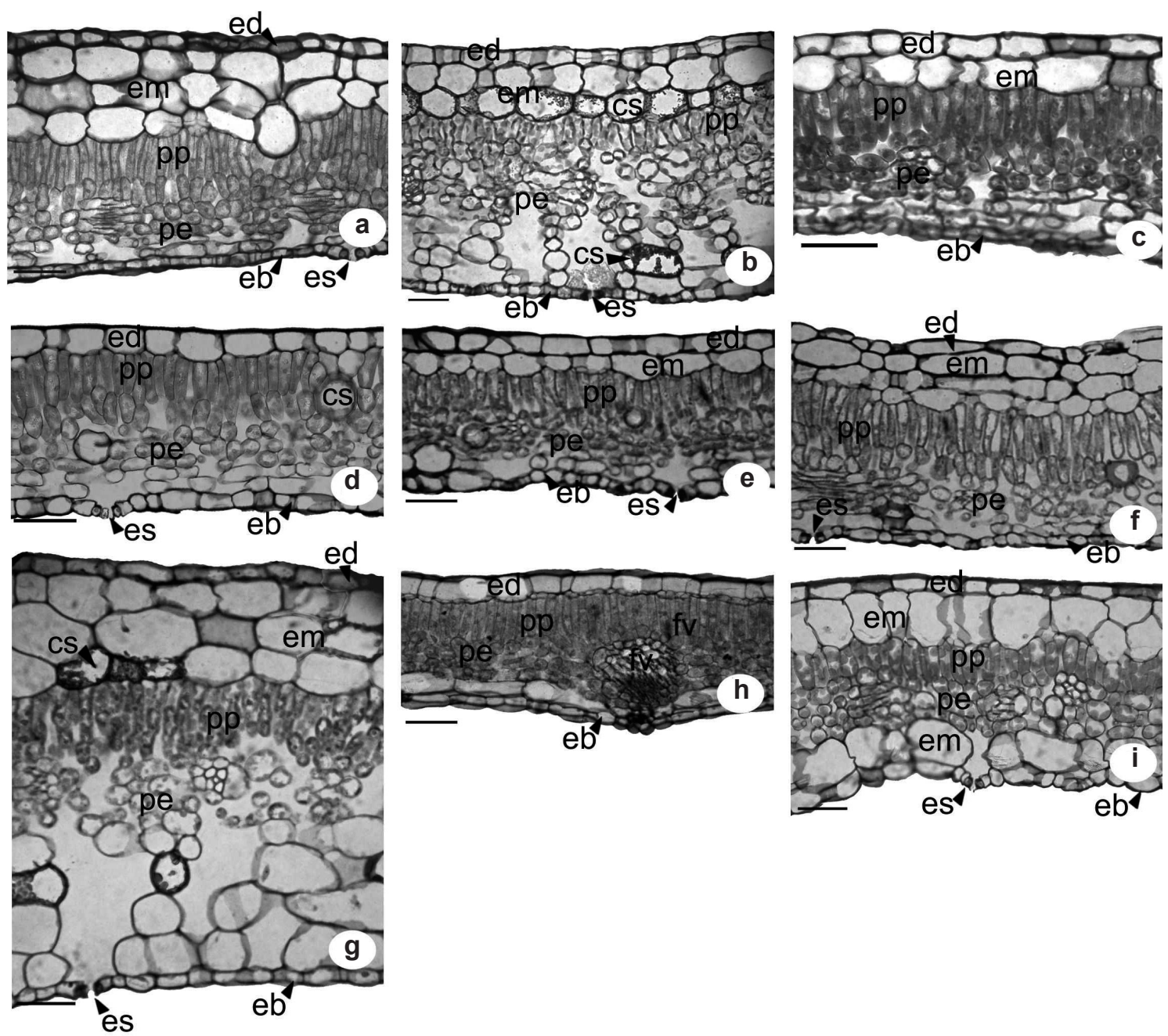

es

eb

Figura 1 - Secções transversais da lâmina foliar: a. Piper aduncum; b. P. cernuum; c. P. dilatatum; d. P. gaudichaudianum; e. P. glabratum; f. P. hispidinervum; g. P. lindbergii; h. P. solmsianum; i. P. umbellatum (cs: célula secretora; eb: epiderme abaxial; ed: epiderme adaxial; em: epiderme múltipla; es: estômato; fv: feixe vascular; pe: parênquima esponjoso; pp: parênquima paliçádico). Escala: $50 \mu \mathrm{m}$.

Figure 1 - Cross sections of leaf blade: a. Piper aduncum; b. P. cernuum; c. P. dilatatum; d. P. gaudichaudianum; e. P. glabratum; f. P. hispidinervum; g. P. lindbergii; h. P. solmsianum; i. P. umbellatum (cs: secretory cells; eb: lower epidermis; ed: adaxial epidermis; em: multiple epidermis; es: stomata; fv: vascular bundle; pe: spongy parenchyma; pp: palisade parenchyma). Bar: $50 \mu \mathrm{m}$.

as primeiras camadas de células da lâmina foliar de várias espécies de Peperomia, constituem uma epiderme múltipla, pois tais células se desenvolvem a partir de divisões periclinais da protoderme. A presença de epiderme múltipla em Peperomia está relacionada principalmente com ambientes bem iluminados, onde tal tecido, de acordo com sua espessura, pode agir como um filtro, regulando a intensidade luminosa para o interior da folha (Takemori 2002; Takemori et al. 2003). Em estudos morfológicos e anatômicos Souza et al. (2004) descreveram em Peperomia dahlstedtii C.DC., Ottonia martiana Miq. e Piper diospyrifolium Kunth que as primeiras camadas de células são epiderme múltipla. Kaul (1977) também constatou a presença de epiderme múltipla em Peperomia, assim como Cutter (1971) relata para o gênero Piper. No presente trabalho optou-se por usar o termo epiderme múltipla, em função das evidencias da origem a partir da protoderme constatadas em artigos consultados sobre espécies de Piperaceae (Cutter 1971; Kaul 1977; Takemori 2002; Takemori et al. 2003; Souza et al. 2004). No entanto, apenas a 

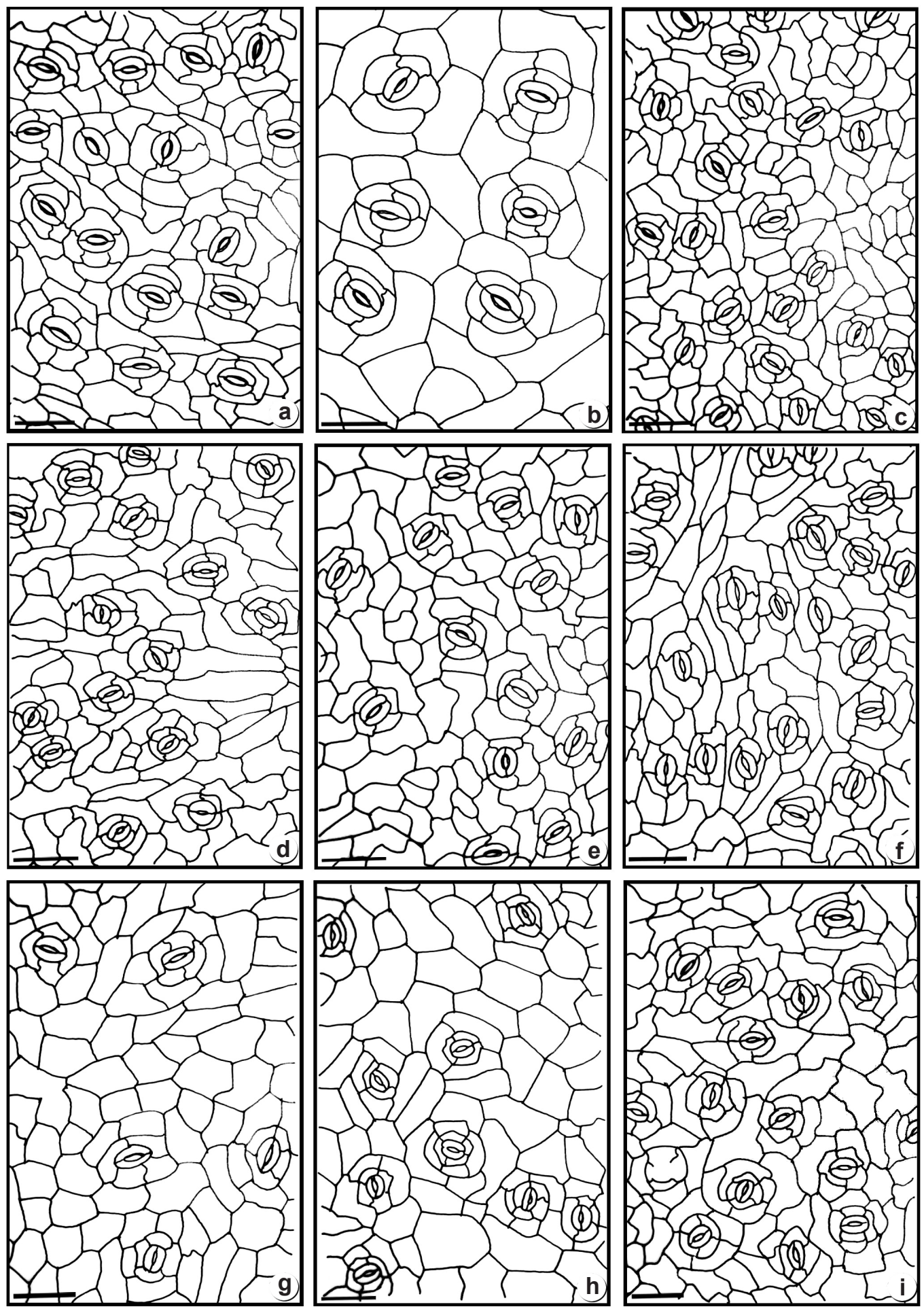

Figura 2 - Secções paradérmicas da lamina foliar evidenciando os estômatos: a. Piper aduncum; b. P. cernuum; c. P. dilatatum; d. P. gaudichaudianum; e. P. glabratum; f. P. hispidinervum; g. P. lindbergii; h. P. solmsianum; i. P. umbellatum. Escala: $50 \mu \mathrm{m}$.

Figure 2 - Paradermic sections of leaf blade showing stomata: a. Piper aduncum; b. P. cernuum; c. P. dilatatum; d. P. gaudichaudianum; e. P. glabratum; f. P. hispidinervum; g. P. lindbergii; h. P. solmsianum; i. P. umbellatum. Bar: 50 $\mu$ m. 


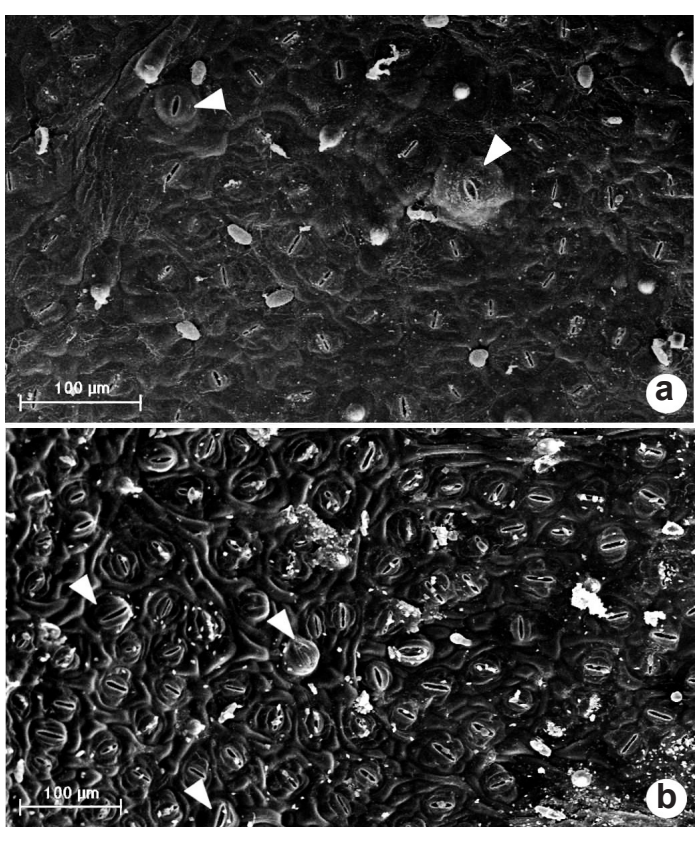

Figura 3 - Estômatos ("setas") em microscopia eletrônica: a. P. gaudichaudianum Kunth.; b. P. hispidinervum C. DC.

Figure 3-Stomata ("arrows") in scanning electron microscopy: a. P. gaudichaudianum Kunth.; b. P. hispidinervum C. DC.

partir de estudos ontogenéticos específicos seria possível concluir para as espécies estudadas, se realmente se trata de epiderme múltipla ou tecido hipodérmico.

A nervura central da maioria das espécies analisadas é proeminente na face abaxial (Fig. 4a-i). Nota-se que em Piper solmsianum e P. umbellatum também há proeminência da nervura central na face adaxial, porém menor do que na face abaxial (Fig. 4h-i). No córtex há tecido colenquimático do tipo angular em todas as espécies analisadas (Figs. 4 e 5). O colênquima está presente tanto na face abaxial, quanto na face adaxial, formando cordões (Fig. 4). O número de camadas de colênquima é bastante variável (Fig. 5a-r). Nota-se que na face abaxial de $P$. cernum e $P$. lindbergii, o tecido colenquimático encontra-se intercalado com o parenquimático (Fig. 4b, g). Nas demais espécies, o colênquima ocorre em faixas contínuas (Fig. 4a, c-f, h-i). Na região adaxial de $P$. aduncum, $P$. dilatatum, $P$. gaudichaudianum e $P$. glabratum, o tecido colênquimático está distribuído de forma mais concentrada, variando apenas no número de camadas (Fig. 5a, c-e). Por outro lado, em $P$. cernuum, P. hispidum, P. lindbergii, P. solmsianum e P. umbellatum, o colênquima está distribuído de forma mais distendida (Fig. 5b, f-i). Na face abaxial, o número de camadas do colênquima também é variável entre as espécies estudadas (Fig. 5j-r).

O número de feixes colaterais na nervura central é diferente para a maioria das espécies, bem como seu tamanho (Fig. 4). Em Piper glabratum e $P$. solmsianum, por exemplo, foi observado apenas um feixe vascular (Fig. 4e, h), enquanto que em $P$. lindbergii foram observados seis feixes vasculares (Fig. 4g). Nas espécies $P$. aduncum, $P$. gaudichaudianum e $P$. umbellatum notam-se três feixes vasculares (Fig. 4a, d, i), já em $P$. cernuum e $P$. dilatatum foram constados quatro feixes vasculares (Fig. 4b-c). Albiero et al. (2006) destacam para P. hispidum a presença de dois feixes vasculares na região mediana do limbo, enquanto que em $P$. crassinervium foi observado apenas um feixe (Albiero et al. 2005a). Em P. gaudichaudianum, Albiero et al. (2005b) e Albiero et al. (2006) registraram oito feixes vasculares na base da folha e um feixe vascular na região mediana e apical da folha. Entretanto, no presente estudo foram observados três feixes vasculares na região mediana para esta mesma espécie (Fig. 4d). Metcalfe \& Chalk (1965), Hutchinson (1973) e Cronquist (1981) comentam que os feixes vasculares em Piperaceae são bastante semelhantes aos feixes das Monocotiledôneas.

$\mathrm{Na}$ maioria das espécies estudadas ocorrem células secretoras, idioblastos (com cristais prismáticos, romboédricos e ráfides), tricomas tectores e glandulares. Além disso, foi constatada a presença de conteúdos lipídicos, grãos de amido e compostos fenólicos nas células de parênquima, localizadas na região da nervura central, bem como no mesofilo da folha. $\mathrm{O}$ amido está presente em todas as espécies estudadas, exceto em P. cernuum. Compostos fenólicos foram observados na maioria das espécies, exceto em $P$. aduncum, $P$. solmsianum e P. umbellatum. Também foram constatados lipídios em todas as espécies analisadas. Foram observadas, na maioria das espécies, células secretoras entre os tecidos do mesofilo da folha (Fig. 1b, d, g) e na região da nervura central, nos tecidos de colênquima e parênquima (Fig. 5b, c, g, k, n-p). Segundo Metcalfe \& Chalk (1965) e Fahn (1988), tais estruturas são comuns em Piperaceae. Em $P$. cernuum e $P$. lindbergii destacam-se a presença de estruturas secretoras articuladas, em fileiras e individualizadas, com conteúdos densos 


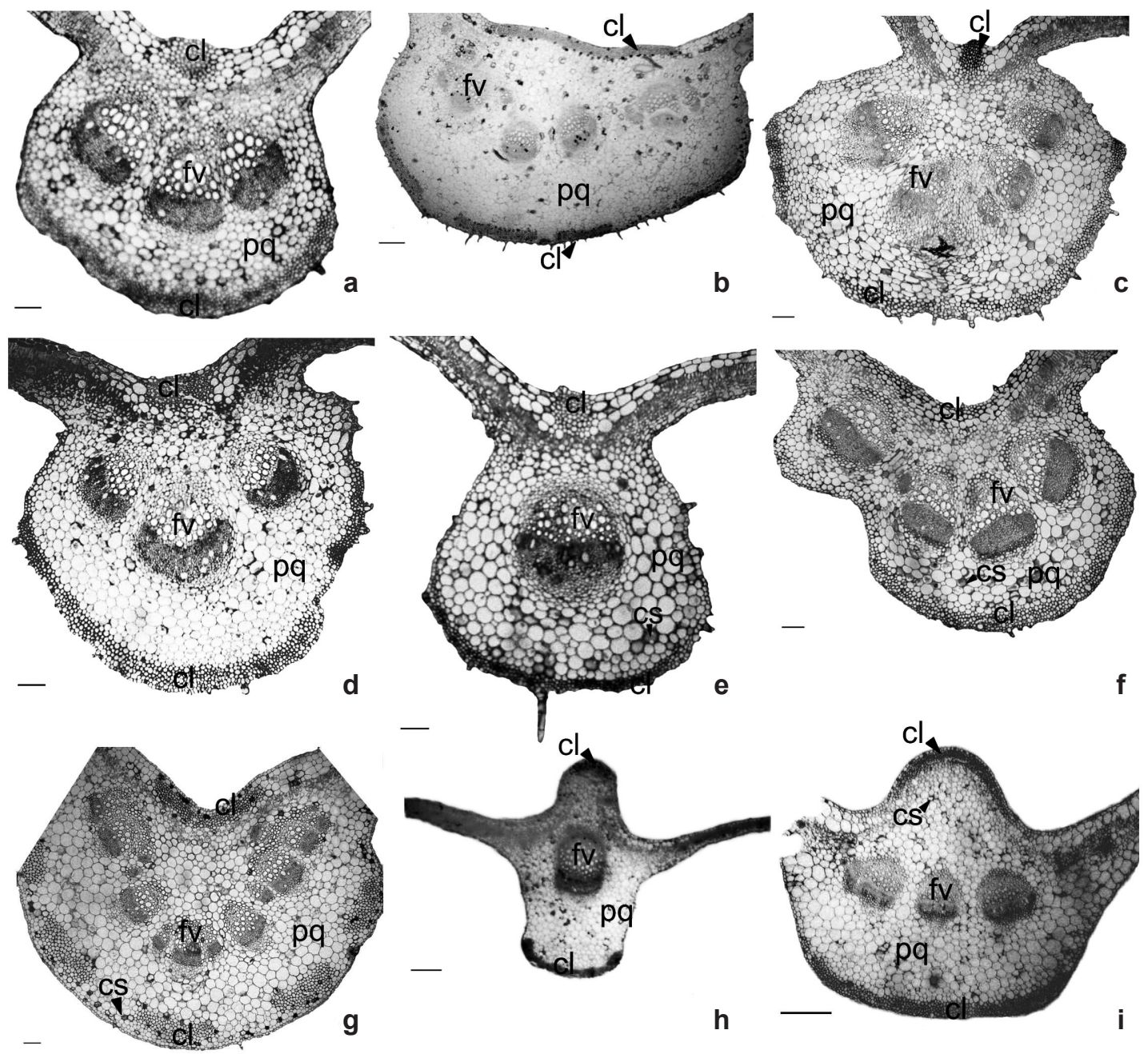

Figura 4-Secção transversal da nervura central: a. Piper aduncum Vell.; b. P. cernuum Vell.; c. P. dilatatum Rich; d. P. gaudichaudianum Kunth; e. P. glabratum Kunth; f. P. hispidinervum C. DC.; g. P. lindbergii C. DC.; h. P. solmsianum C. DC. e i. P. umbellatum Jacq. (cl: colênquima; cs: célula secretora; fv: feixe vascular; pq: parênquima). Escalas: $300 \mu \mathrm{m}(\mathrm{b}, \mathrm{h}, \mathrm{i}) ; 100 \mu \mathrm{m}$ (a, c, d, e, f, g).

Figure 4-Cross sections of the midvein: a. Piper aduncum Vell.; b. P. cernuum Vell.; c. P. dilatatum Rich; d. P. gaudichaudianum Kunth; e. P. glabratum Kunth; f. P. hispidinervum C. DC.; g. P. lindbergii C. DC.; h. P. solmsianum C. DC. and i. P. umbellatum Jacq. (cl: collenchyma; cs: secretory cells; fv: vascular bundle; pq: parenchyma). Bar: $300 \mu \mathrm{m}$ (b, h, i); $100 \mu \mathrm{m}$ (a, c, d, e, f, g).

de diferentes formatos, em praticamente todos os tecidos da folha, constituídos por óleos essenciais. Células semelhantes, com óleo essencial, foram observadas em espécies de Peperomia e Piper diospyrifolium (Souza et al. 2004). Santos et al. (2001) realizaram um estudo identificando os diferentes tipos de óleos essenciais em 10 espécies de Piperaceae no Brasil, ocorrentes em Floresta Atlântica, concluindo que o composto mais comum para esta família são os sesquiterpenos.
Dentre as características observadas na estrutura das folhas de Piper, a mais relevante e que permite maior diferenciação entre as espécies são os tricomas (Fig. 6a-h). Estes, segundo Metcalfe \& Chalk (1965), ocorrem praticamente em todas as espécies da família Piperaceae. Os tricomas são frequentes principalmente na face abaxial da folha. A maioria das espécies analisadas tem tricomas glandulares, tectores unie multicelulares, unisseriados, com ornamentações 

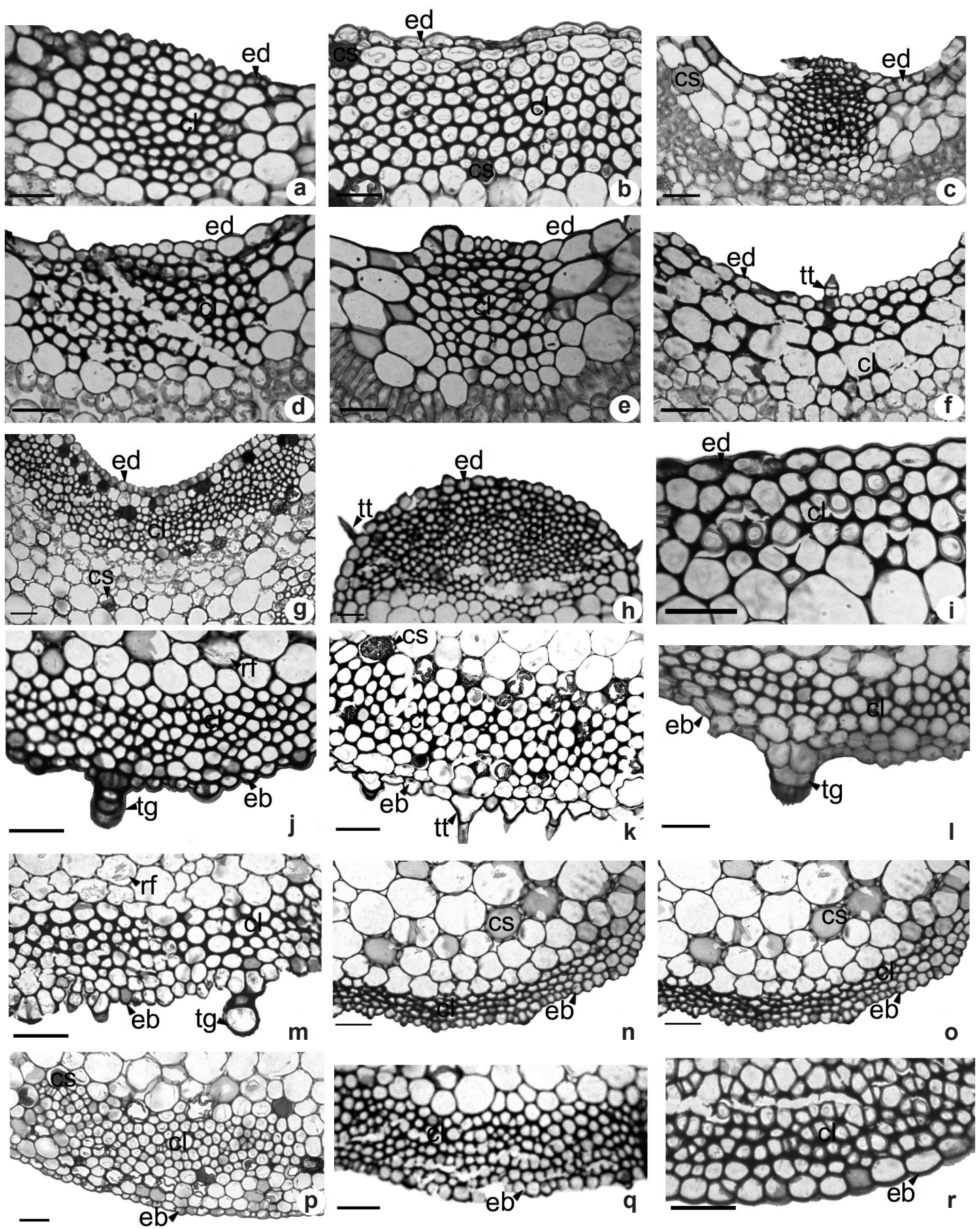

Figura 5 - Seç̧ões transversais da nervura central evidenciando colênquima: a-i. face adaxial e j-r. face abaxial. a, j. Piper aduncum; b, k. P. cernuum; c, 1. P. dilatatum; d, m. P. gaudichaudianum; e, n. P. glabratum; f, o. P. hispidinervum; g, p. P. lindbergii; h, q. P. solmsianum; i, r. P. umbellatum. (cl: colênquima; cs: célula secretora; eb: epiderme abaxial; ed: epiderme adaxial; rf: ráfide; tg: tricoma glandular; tt: tricoma tector). Escala: $50 \mu \mathrm{m}$. Figure 5-Cross sections of the midvein showing collenchyma in the adaxial and abaxial surfaces, respectively: a,j. Piper aduncum; b,

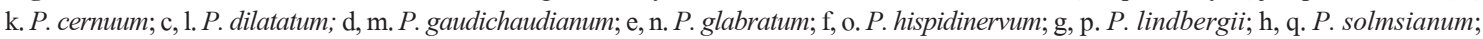
i, r. P. umbellatum. (cl: collenchyma; cs: secretory cells; eb: epidermis abaxial; ed: epidermis adaxial; rf: raphid; tg: glandular trichome; tt: trichome). Bar: $50 \mu \mathrm{m}$. 


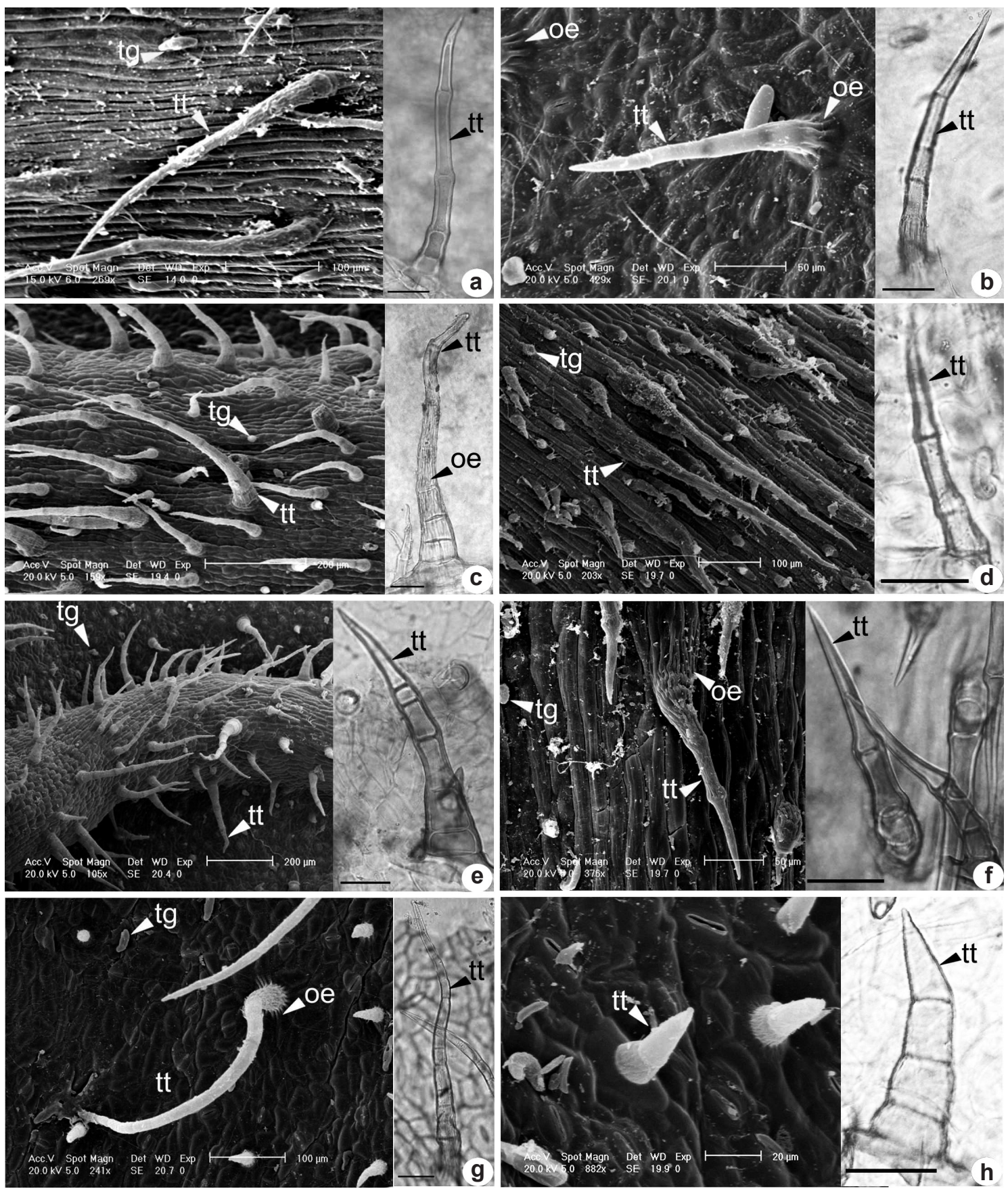

Figura 6 - Tricomas em microscopia eletrônica de varredura e vista frontal: a. Piper aduncum; b. P. cernuum; c. P. dilatatum; d. P. gaudichaudianum; e. P. glabratum; f. P. hispidinervum; g. P. lindbergii; h. P. solmsianum (oe: ornamentações epicuticulares; tg: tricoma glandular; tt: tricoma tector). Barra: $50 \mu \mathrm{m}$.

Figure 6 - Trichomes in scanning electron microscopy and frontal view: a. Piper aduncum Vell.; b. P. cernuum Vell.; c. P. dilatatum Rich; d. P. gaudichaudianum Kunth; e. P. glabratum Kunth; f. P. hispidinervum C. DC.; g. P. lindbergii C. DC.; h. P. solmsianum C. DC. (oe: cuticular ornamentation; tg: glandular trichome; tt: trichome). Bar: $50 \mu \mathrm{m}$. 
epicuticulares, porém bastante diversificados quanto à forma e ao tamanho (Fig. 6a-h). O tamanho dos tricomas tectores pode variar entre curto e longo (Fig. 6a-h). O ápice varia de agudo a arredondado e a base pode ter ornamentações epicuticulares (Fig. 6b-c, f-g). Metcalfe \& Chalk (1965) mencionam que os tricomas raramente formam uma densa cobertura, são geralmente unisseriados e compostos por pequeno número de células. Neste estudo foram encontrados tricomas unisseriados com grande número de células para a maioria das espécies estudadas (Figura 6a-h). Foram constatados que os tricomas são menores em P. umbellatum (Fig. 6h), quando comparado com as demais espécies (Fig. 6a-g). Piper cernuum, P. hispidinervum e P. lindbergii apresentam como característica relevante a presença de ornamentações epicuticulares bem marcadas na base do tricoma tector (Fig. 6b, f-g), porém, em $P$. dilatatum as ornamentações são levemente marcadas (Fig. 6c). Nota-se que em $P$. hispidinervum as ornamentações epicuticulares se estendem da base até a região mediana do tricoma (Fig. 6f). Além disso, os tricomas glandulares de P. hispidinervum têm pedicelo curto (Fig. 5f), característica também observada em $P$. hispidum (Albiero et al. 2006). Foram constatados que em $P$. lindbergii as ornamentações epicuticulares são mais finas e estão apenas na região basal do tricoma (Fig. 6g). Em P. gaudichaudianum os tricomas tectores são longos e o ápice é agudo (Fig. 6d). Entretanto, o tricoma glandular nessa espécie tem a porção apical secretora, unicelular e ovóide (Fig. 5h). Tal descrição suporta os resultados observados por Albiero et al. (2005b). Em $P$. solmsianum não foram observados tricomas.

A análise de agrupamento, com base nas características selecionadas (Tab. 1), organizou as espécies estudadas em três grandes grupos, sendo que os coeficientes de distanciamento variaram entre 2,2 e 3,4, com os valores de UPGMA entre 2,2 a 3,6, enquanto o índice cofenético foi de $0,74(\mathrm{P}<0,001)$. Piper solmsianum e $P$. umbellatum apresentam a maior similaridade entre as espécies, seguido de $P$. gaudichaudianum que é a espécie mais próxima desse grupo (Fig. 7). Características como a presença de epiderme múltipla em ambas as faces do limbo, cutícula espessa e paredes celulares retas, são típicas em $P$. solmsianum e $P$. umbellatum, bem como em $P$. gaudichaudianum, sendo que nesta última espécie só não ocorre à presença da epiderme múltipla na face adaxial (Tab. 1). O segundo grupo é formado por $P$. cernuum, $P$. dilatatum, $P$. glabratum e $P$. lindbergii que têm em comum a presença de uma epiderme sinuosa, com cutícula delgada, epiderme múltipla apenas na face abaxial com duas a três camadas, colênquima formado por cinco ou mais camadas além da presença de compostos fenólicos e tricomas longos (Tab. 1). Piper aduncum e $P$. hispidum, formaram o terceiro grupo, com maior grau de dissimilaridade (Fig. 7), sendo que esse último grupo caracteriza-se pela presença de estômatos com quatro células anexas, duas camadas de parênquima paliçádico e três camadas de parênquima lacunoso, três feixes vasculares e amido (Tab. 1).

Apesar das espécies aqui estudadas apresentarem características morfo-anatômicas semelhantes, foram observadas características anatômicas que podem ser consideradas diagnósticas como: epiderme múltipla, espessura da cutícula, sinuosidade da parede celular, número de camadas dos parênquimas clorofilianos e tamanho dos tricomas, como evidenciado pela análise de agrupamento. Tais dados reforçam o uso potencial de características anatômicas foliares na diferenciação de espécies.

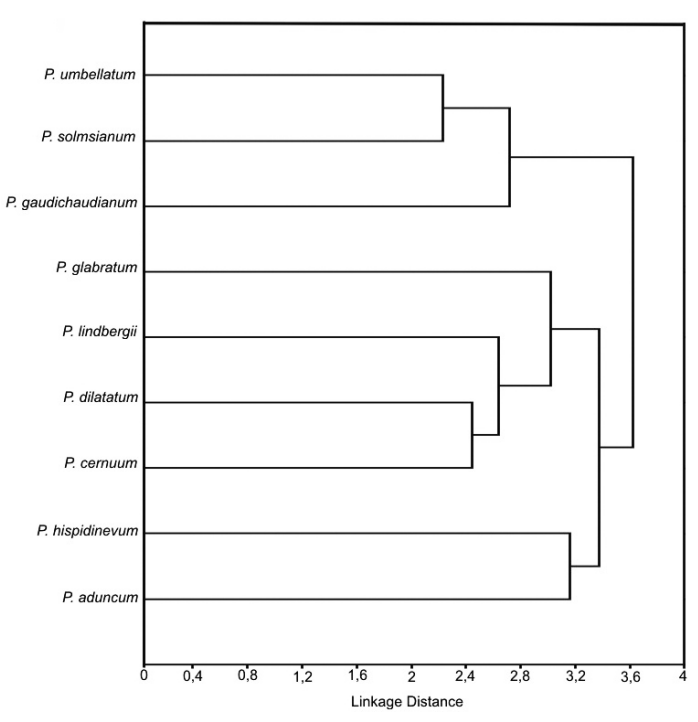

Figura 7-Análise de agrupamento obtida por distância Euclediana e UPGMA, de espécies de Piper, com base em ausência ou presença de caracteres anatômicos da folha. Figure 7 - Cluster analysis obtained with Euclidean distance and UPGMA alogarithm, of species of Piper, based on absence and presence of leaf anatomical characters. 


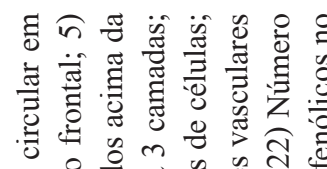

ช

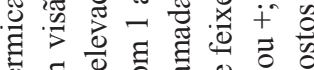

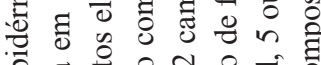

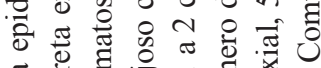

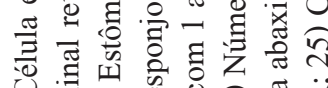

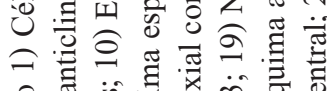

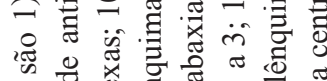
की 离

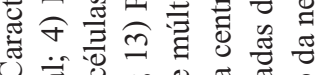

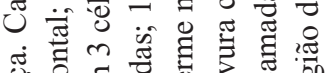

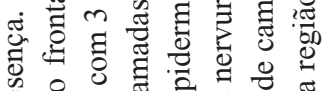
论

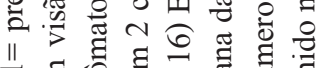

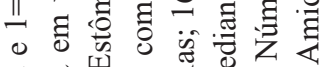

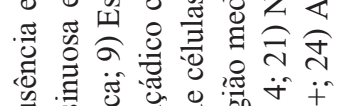

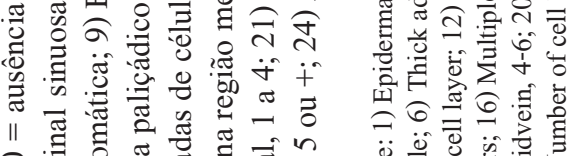

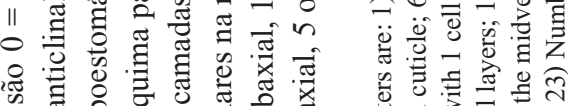

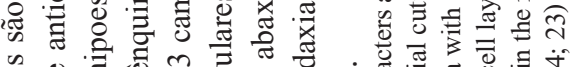

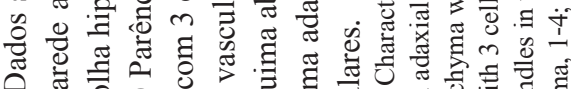
ค

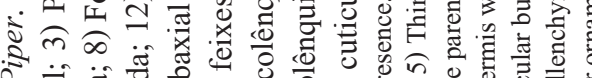

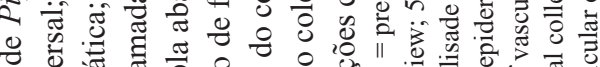
ర

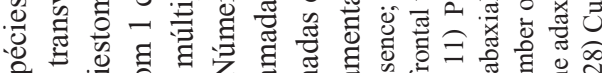

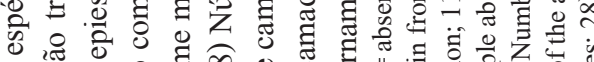
๑

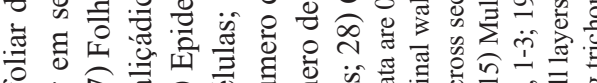

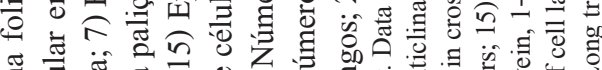

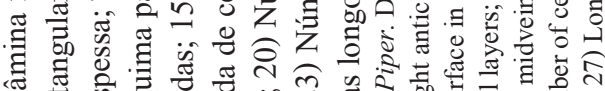

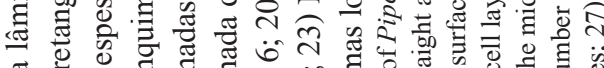
๘

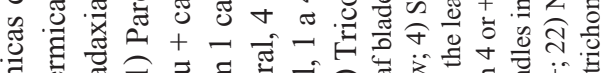

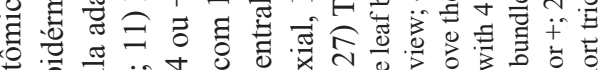

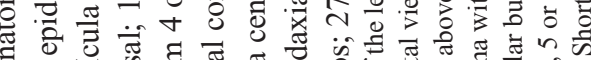

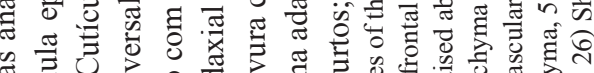

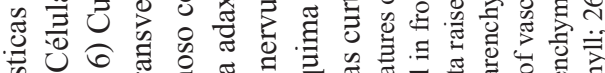

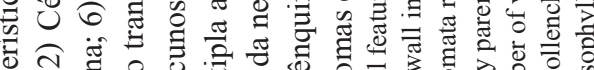

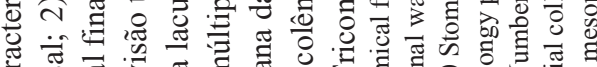

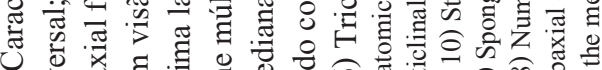

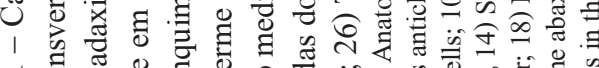

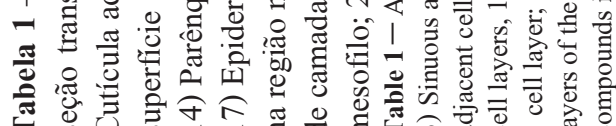

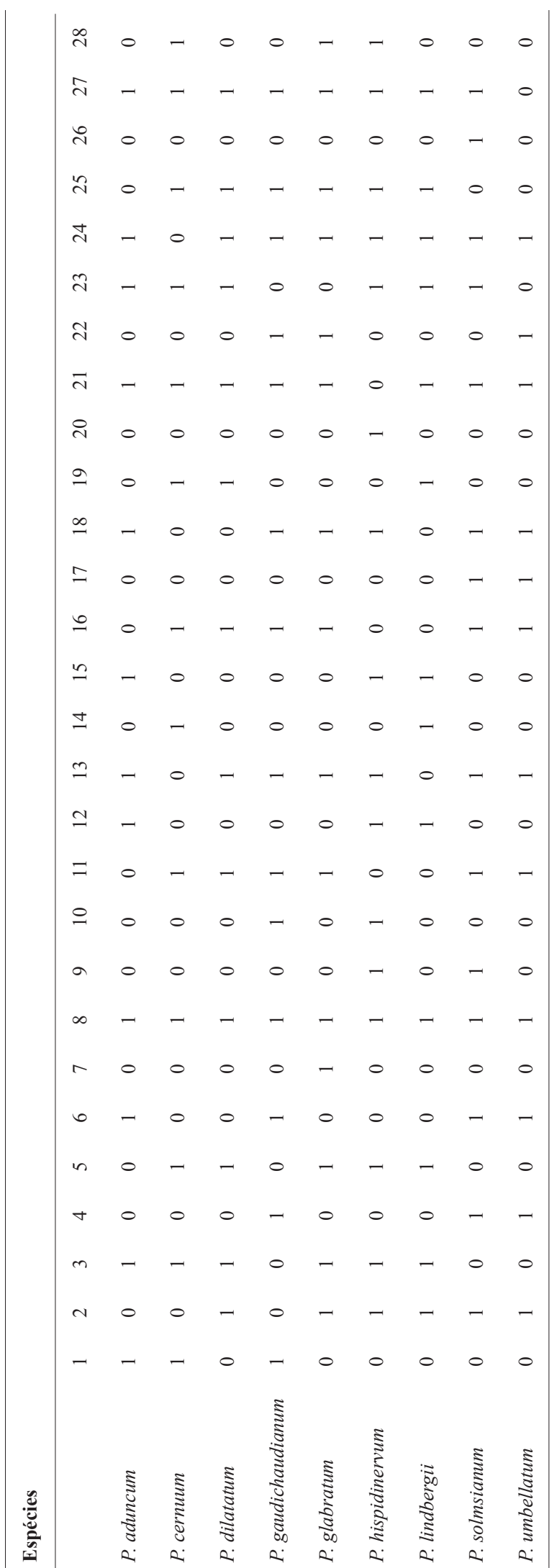




\section{Referências}

Albiero, A.L.M.; Paoli, A.A.S.; Souza, L.A. \& Mourão, K.S.M. 2005a. Morfoanatomia dos órgãos vegetativos de Piper crassinervium H.B. \& K. (Piperaceae). Acta Botanica Brasilica 19: 305-312.

Albiero, A.L.M.; Souza, L.A.; Mourão, K.S.M.; Almeida, O.J.G. \& Lopes, W.A.L. 2005b. Morfo-anatomia do caule e da folha de Piper gaudichaudianum Kuntze (Piperaceae). Acta Farmaceutica Bonaerense 24: 550-554.

Albiero, A.L.M.; Paoli, A.A.S.; Souza, L.A \&; Mourão, K.S.M. 2006. Morfoanatomia dos órgãos vegetativos de Piper hispidum Sw. (Piperaceae). Revista Brasileira de Farmacognosia 16: 379-391.

Berlyn, G.P. \& Miksche, J.P. 1976. Botanical microtechnique and cytochemistry. The Iowa State University Press, Ames. 326p.

Cutter, E.G. 1971. Plant Anatomy: experiment and interpretation. Addison-Wesley Publishing Company, University California, Davis. 343p.

Cronquist, A. 1981. An integrated system of classification of flowering plants. Columbia University Press, New York. 1262p.

Embrapa - Centro Nacional de Pesquisa de Solos. 1999. Sistema brasileiro de classificação de solos. Embrapa Produção de Informações, Brasília; Embrapa Solos, Rio de Janeiro. 412p.

Facundo, V.A.; Silveira, A.S.P.; Morais, S.M. 2005. Constituents of Piper alatabaccum Trel Yuncker (Piperaceae). Biochemical Systematics and Ecology 33: 753-756.

Fahn, A. 1988. Secretory tissues in vascular plants. New Phytologist 108: 229-257.

Guimarães, E.F. \& Valente, M.C. 2001. Piperaceae Piper. In: Reitz, R. (ed.). Flora ilustrada catarinense. Herbário Barbosa Rodrigues, Itajaí.

Hutchinson, J. 1973. The families of the flowering plants. 3th. ed. Claredon Press, London. 968p.

Johansen, D.A. 1940. Plant microtechnique. McGraw Hill Book, New York. 523p.

Kaul, R. 1977. The role of the multiple epidermis in foliar succulence of Peperomia (Piperaceae). Botanic Gazette 138: 213-218.

Kraus, J.P. \& Arduin, M. 1997. Manual básico de métodos em morfologia vegetal. EDUR, São Paulo, Seropédica. $198 \mathrm{p}$.

Machado, N.S.O. 2007. Estudo da anatomia foliar de espécies do gênero Piper L. (Piperaceae) no estado do Rio de Janeiro. Tese de Doutorado. Universidade Federal do Rio de Janeiro, Rio de Janeiro. 103p.

Martins, A.P.; Salgueiro, L.; Vila, R.; Tomi, F.; Canigueral, S.; Casanova, J.; Proença da Cunha, A. \& Adzet, T. 1998. Essential oils from four Piper species. Phytochemistry 49: 2019- 2023.
Metcalfe, C.R. \& Chalk,L. 1965. Anatomy of the dicotyledons. Vol. 2. Clarendon Press, Oxford. Pp. 725-1500.

Metcalfe, C.R. \& Chalk,L. 1979. Anatomy of the dicotyledons: systematic anatomy of leaf and stem, with a brief history of the subject. 2nd ed. Vol. 1 . Clarendon Press, Oxford. 276p.

Morais, S.M.; Facundo, V.A.; Bertini, L.M.; Cavalcanti, E.S.B.; Júnior, J.F.A.; Ferreira, S.A.; Brito, E.S.; Neto, M.A.S. 2007. Chemical composition and larvicidal activity of essential oils from Piper species. Biochemical Systematics and Ecology 35: 670-675.

Mundina, M.; Vila, R.; Tomi, F.; Tomás, X.; Cicció, J.F.; Adzet, T.; Casanova, J. \& Canigueral, S. 2001. Composition and chemical polymorphism of the essential oils from Piper lanceaefolium. Biochemical Systematics and Ecology 29: 739-748.

O’Brien, T.P.; Feder, N. \& McCully, M.E. 1964. Polychromatic staining of plant cell walls by toluidine blue O. Protoplasma 59: 368-373.

Parmar, V.S.; Jain, S.C.; Bisht, K.S.; Jain, R.; Taneja, P.; Jha, A.; Tyag, O.D.; Prasad, A.K.; Wengel, J.; Olsen, C.E. \& Boll, P.M. 1997. Phytochemistry of the genus Piper. Phytochemistry 46: 591-673.

Santiago, E.J.A.; Pinto, J.E.B.P.; Castro, E.M.; Lameira, O.A.; Conceição, H.E.O. \& Gavilanes, M.L. 2001. Aspectos da anatomia foliar da pimenta-longa (Piper hispidinervium C.DC.) sob diferentes condições de luminosidade. Ciência e Agrotecnologia, Lavras 25: 1035-1042.

Santos, P.R.D.; Moreira, D.L.; Guimarães, E.F. \& Kaplan, M.A.C. 2001. Essential oil analysis of 10 Piperaceae species from the Brazilian Atlantic forest. Phytochemistry 58: 547-551.

Sass, J.E. 1951. Botanical microtechnique. 2ed. Iowa State College Press, Iowa. 228p.

Silva, A.C.P.R. \& Oliveira, M.N. 2000. Caracterização botânica e química de três espécies do gênero Piper no Acre. Boletim de Pesquisa 23. Embrapa Acre, Rio Branco. 13p.

Smith, W.K.; Vogelmann, T.C.; DeLucia E.H.; Bell, D.T. \& Shepherd, K.A. 1997. Leaf form and photosynthesis. Bioscience 47:785-793.

Sousa, P.J.C.; Barros, C.A.L.; Rocha, J.C.S.; Lira, D.S.; Monteiro, G.M. \& Maia, J.G.S. 2008. Avaliação toxicológica do óleo essencial de Piper aduncum L. Revista Brasileira de Farmacognosia 18: 217-221.

Souza, L.A.; Albiero, A.L.M.; Almeida, O.J.G.; Lopes, W.A.L.; Mourão, K.S.M. \& Moscheta, I.S. 2009. Estudo morfo-anatômico da folha e do caule de Piper arboreum Aubl. (Piperaceae). Latin American Journal of Pharmacy 28: 103-107.

Souza, L.A.; Moscheta, I.S. \& Oliveira, J.H.G. 2004. Comparative morphology and anatomy of the leaf and stem of Peperomia dahlstedtii C.DC., Ottonia 
martiana MIQ. and Piper diospyrifolium Kunth (Piperaceae). Gayana Botánica 61: 6-17.

Souza, V.C. \& Lorenzi, H. 2005. Botânica sistemática: guia ilustrado para identificação das famílias da Angiospermas da flora brasileira, baseado em APGII. Instituto Plantarum, Nova Odessa. 640p.

Takemori, N.K. 2002. Anatomia comparada de Peperomia catharinae Miquel, P. emarginella (Sw.) C.DC., $P$ quadrifolia (L.) Kunth e $P$. rotundifolia
(L.) Kunth (Piperaceae). Dissertação de Mestrado. Universidade Federal do Paraná, Curitiba. 53p.

Takemori, N.K.; Bona, C. \& Alquini, Y. 2003. Anatomia comparada das folhas de espécies de Peperomia (piperaceae) - I. Ontogênese do tecido aqüífero e dos estômatos. Acta Botanica Brasilica 17: 387-394.

Taiz, L. \& Zeiger, E. 2004. Fisiologia vegetal. 3rd ed. Artmed, Porto Alegre. 719p. 